\title{
PENSAMENTO FEMINISTA BRASILEIRO: PENSADORAS E PRODUÇÕES TEÓRICAS
}

Veridiana Pereira Parahyba Campos ${ }^{\mathrm{I}}$

I Núcleo de Estudos da Violência (NEV) Universidade de São Paulo (USP), São Paulo (SP), Brasil; veridianacampos01@gmail.com

Hollanda, H. B. de (Org.) (2019). Pensamento feminista brasileiro: Formação e contexto. Bazar do Tempo. 400p. ISBN 978-85-69924-50-0.

Organizado por Heloísa Buarque de Hollanda, esse livro deve ser item obrigatório em qualquer estante que se preze, para entender tanto a história do pensamento social brasileiro quanto a formação de nosso(s) feminismo(s) tupiniquim(ns). ${ }^{1}$

A obra é um manancial; apresenta introdução elaborada pela organizadora e mais 19 artigos de 20 outras autoras, remontando a colcha de retal hos concomitantemente tecida nas dimensões científica, epistemológica e política que formaram o, assim nomeado, pensamento feminista brasileiro.

Dentre os 19 artigos, bastante heterogêneos entre si, nem todos são necessariamente "novos"; há material produzido desde 1976 até 2018 e, por isso, o conteúdo de Pensamento feminista brasileiro: Formação e contexto (PFB, de agora em diante) nos conduz a um verdadeiro túnel do tempo, só que de maneira não linear. A ausência de uma ordem cronológica na disposição dos textos conduz leitoras e leitores a diferentes tempos e espaços de passados distantes e recentes.

A obra se divide em quatro eixos temáticos: "Algumas histórias sobre o feminismo no Brasil"; "Bandeiras tornam-se objeto de estudo"; "Interseccionalidades: pioneiras no feminismo brasileiro"; e "Em busca de novos caminhos críticos". Por meio dessa divisão, o livro estrutura uma organização heurística refinada e bastante funcional para eventuais pesquisas no conteúdo.

A introdução de PFB, escrita pela própria Heloísa, é um prazer à parte, na qual ela traz algumas "perolinhas" da história feminista "brazuca", dividindo conosco sua inspiração de reunir todo esse material. A ideia é que as jovens feministas possam beber no pensamento das veteranas, mulheres tão fundamentais para a sedimentação de um movimento-teoria social que, até hoje, provoca sentimentos ambíguos na sociedade. 


\section{Aspectos gerais de interesse na obra}

Antes de falarmos sobre cada artigo individualmente, demarcamos alguns aspectos gerais do material como um todo, considerados de bastante interesse e que tornam a obra especial.

O primeiro é que, além de produção teórica de peso, leitoras e leitores de PFB encontrarão ali algo como a "construção subjetiva" das pensadoras. Bastante plurais entre si, os artigos "secretam" como essas mulheres foram se descobrindo e se assumindo feministas, compromissadas em trabalhar as questões da desigualdade de gênero, endo e exogenamente, subjetiva e socialmente.

Há todo um processo de definição conceitual e de autorreconhecimento, contado (in) diretamente no decorrer dos artigos. Já na introdução, descobrimos que feministas da envergadura de Heleieth Saffioti, por exemplo, durante muito tempo não se reconheceram como tal. A titulação "feminista" não era bem-vista nos círculos científicos e políticos nos primórdios desse campo de estudos e, por isso, a resistência em assumi-la.

Hoje, 50 anos depois, mesmo reapropriado e fortalecido, o termo ainda não é bem-visto (nem bem-compreendido) em todo e qualquer contexto. Além disso, brincando com Beauvoir, a verdade é que ninguém nasce feminista; trata-se de uma formação processual. Na biografia da própria Heloisa Buarque de Hollanda, também observamos que ela foi se constituindo uma pesquisadora da área (ou feminista assumida?) no decorrer de sua jornada. Seu objeto de estudo/interesse principal, quando assumiu o cargo de professora titular da Universidade Federal do Rio de Janeiro (UFRJ), era a teoria crítica da cultura.

Essas informações mais pessoais de duas veteranas do feminismo brasileiro vêm relembrar ao público que, recorrentemente, observamos uma conexão entre subjetividade e interesse científico em estudos feministas. Os artigos apresentam essa recorrência diversas vezes. $\mathrm{Na}$ caminhada de mulheres que pensam a si próprias, para além de uma perspectiva de mundo, o feminismo vira um objeto científico interessante.

Mais além, podemos afirmar que o estudo e a prática feministas são congruentes com qualquer área de trabalho, seja ela científica ou não. A imersão nessa epistemologia está muito mais conectada à afinidade pessoal com um ideal social inclusivo e equânime do que com alguma pré-formação técnico-científica; daí, parecer-nos possível que qualquer pessoa, de qualquer gênero ou sexo, possa ser feminista.

Inclusive, ainda tratando da formação feminista subjetiva, o livro ressalta a imensa importância dos "grupos de reflexão" dos idos de 1960/70, nos quais, coletivamente, pela primeira vez de forma sistemática, mulheres comuns discutiram os diversos efeitos - tangíveis ou não - da desigualdade de gênero em suas vidas. Naquele momento, a nomeação dessa desigualdade talvez não fosse exatamente essa, mas, como diria um poeta, se a rosa não se chamasse rosa, ainda assim seu perfume seria o mesmo.

Nesses grupos de reflexão, efeitos seculares do patriarcado foram desvelados; juntas, essas mulheres descobriam que situações de opressão que lhes pareciam privadas se repetiam em outros lares, com matizes muito semelhantes. E, assim, fomos aprendendo um dos principais bastiões do feminismo: o privado é público.

O conjunto dos textos mostra a formação das pesquisadoras, dos objetos de pesquisa, das epistemologias e de toda uma rede que nos permite, hoje, em 2021, afirmar que não há mais um único feminismo, mas sim um conjunto de feminismos que, ainda que tenham a mesma meta - a igualdade de gênero -, diferem nas formas de entendimento sobre como defini-la e alcançá-la.

Outro aspecto geral destacado no material diz respeito ao fato de que o pensamento feminista brasileiro diverge em vários pontos da formação dos pensamentos feministas europeu e estadunidense, os quais, por uma série de razões, são reconhecidos como pioneiros. Tendo sido os primeiros a se institucionalizarem, de fato, atuaram como um farol para as feministas de outras paragens geográficas. 
Nessa seara, a organizadora do livro chama a atenção sobre como, ainda hoje, no Brasil, continuamos apegadas à bibliografia feminista produzida pelo grande eixo. Não que ela deva ser desconsiderada - afinal há muita qualidade na produção estrangeira, além da apresentação de realidades diferentes da nossa -, mas PFB nos traz todo um arcabouço relembrando que podemos (e devemos) consumir a ciência nacional.

Recentemente, a filósofa negra feminista Angela Davis, ${ }^{2}$ em visita ao nosso país, comentou o quanto os Estados Unidos têm a aprender com a antropóloga brasileira Lélia Gonzalez:

Eu me sinto estranha quando sinto que estou sendo escolbida para representar o feminismo negro.

E por que aqui no Brasil vocês precisam buscar essa referência nos Estados Unidos? Eu acho que aprendo mais com Lélia Gonzalez do que vocês poderiam aprender comigo.

Na mesma toada, Patrícia Hill Colins, também feminista negra estadunidense, em conferência na Universidade de São Paulo (USP), em outubro de 2019, ${ }^{3}$ igualmente criticou o fato de Gonzalez ser uma pensadora pouco usada nas referências bibliográficas no nosso país. ${ }^{4}$

\section{Sobre os artigos}

Falemos agora, então, sobre os textos que dão corpo à obra, para despertar ainda mais o interesse em sua leitura.

No primeiro eixo temático, “Algumas histórias sobre o feminismo no Brasil”, são apresentados seis artigos, produzidos entre 1980 e 2018, narrando os primórdios da formação desse pensamento no país. "Feminismo, uma história a ser contada", de Constância Lima Duarte, escrito em 2003, aborda sobre como é preciso remontar e contar a história desse movimento-teoria, dividido pela autora em quatro fases principais: no século XIX, a luta pela educação feminina e pelo voto, e, no século XX, as lutas pelos direitos políticos, cidadania e o auge das conquistas e da legitimação científica nos anos 1970. Já no artigo "A luta das sufragistas", escrito em 1980, Branca Moreira Alves discorre sobre a história das sufragistas brasileiras e suas conexões com as sufragistas estadunidenses e como se forma um campo de mulheres intelectuais politicamente organizadas a partir da viga mestra que era o direito ao voto. Rita Terezinha Schmidt, com sua contribuição "Na literatura, mulheres que reescrevem a nação", de 2000, expõe como um projeto nacionalista do século XIX para uma literatura "tipicamente" brasileira, assimilacionista e pautada pelo romantismo excluiu grandes escritoras cujas literaturas vinham repletas de conteúdo crítico. No artigo mais recente desse eixo, de 2018, Jacqueline Pitanguy retoma e renova a importância da "Carta das mulheres brasileiras aos constituintes", um marco na formação de nosso regime democrático, sendo tal carta a voz "oficial" feminina num contexto de elaboração constitucional. Bila Sorj traz "O feminismo na encruzilhada da modernidade e pós-modernidade", de 1992, em que mostra sem pudor uma série de ambiguidades da teorização feminista, já tendo esse texto se tornado um clássico nos bancos acadêmicos. O primeiro eixo se encerra, então, com o artigo coletivo de Albertina de Oliveira Costa, Carmen Barroso e Cynthia Sarti, "Pesquisa sobre a mulher no Brasil: do limbo ao gueto?”, de 1985, no qual as autoras questionam e descrevem as pesquisas com mulheres e sobre mulheres no decorrer da história, bem como a importância da perspectiva feminista na sua qualificação e legitimação enquanto objeto científico, ressaltando quão necessário (e difícil) é o aprofundamento teórico nesse campo de estudos.

2 Palestra proferida em 19 de outubro de 2019 no Sesc Pinheiros, na cidade de São Paulo. Para mais informações ver: https://www.brasildefato.com.br/2019/10/20/em-sp-angela-davis-pede-valorizacao-de-feministas-negras-brasileiras

3 Conferência proferida por ela no lançamento do livro o pensamento feminista negro: desafios contemporâneos e novas perspectivas, coordenado pela professora Nadya Araujo.

4 A obra resenhada não pode ser acusada de tal omissão. Lélia Gonzales está lá, com seu artigo clássico "Racismo e sexismo na cultura brasileira", de 1984. 
No segundo eixo temático, "Bandeiras tornam-se objeto de estudo", são apresentados quatro artigos, escritos entre 1991 e 2004, nos quais os temas adentram questões (talvez) mais subjetivas. O primeiro, "Violência de gênero: o lugar da práxis na construção da subjetividade", um clássico de Heleieth Saffioti, de 2004, demarca os sujeitos como múltiplos, constituídos de classe, raça/etnia e gênero, mostrando como essas três identidades sociais seriam flexíveis em termos de preponderância, variando de acordo com o contexto. Ou seja: sem falar de "interseccionalidade" formalmente, é para lá que caminha a conclusão de Saffioti. O segundo artigo, escrito em 1993 por Maria Betânia Ávila, "Modernidade e cidadania reprodutiva", traz a problemática dos direitos reprodutivos e sua ligação intrínseca com a politização dos corpos. Já em "Legalização e descriminalização: dez anos de luta feminista”, Leila Linhares Barsted aponta como, em 1991, o direito ao aborto continuava uma pauta nevrálgica na sociedade e como sua consecução representaria a autonomia das mulheres sobre seus corpos. Parece que continuamos na mesma em 2021. O eixo se encerra com "Mulheres sindicalizadas: classe, gênero, raça e geração na produção de novos sujeitos políticos, um estudo de caso", escrito por Mary Castro, em 1992, no qual são discutidas a relevância da sindicalização das trabalhadoras domésticas e as contradições na segmentação de lutas feministas e trabalhistas, como, por exemplo, a invisibilidade de questões raciais.

Ligado a tal discussão, apresenta-se o mote do terceiro eixo temático da obra: "Interseccionalidades: pioneiras no feminismo brasileiro". O grupo é composto por quatro artigos produzidos por feministas negras entre de 1976 e 2003. O primeiro, da icônica Lélia Gonzalez, "Racismo e sexismo na cultura brasileira", de 1984, traz o estilo ácido e um pouco cômico da autora, que chama o Brasil de "América Africana" e mostra os matizes de um racismo à brasileira. Em seguida, Beatriz Nascimento sistematiza os contornos da situação da "Mulher negra no mercado de trabalho", em 1976, demonstrando como esse grupo tendia a estar eternamente alocado em postos de trabalho que remetem às ocupações de origem escravagista. $\mathrm{O}$ artigo de 1990 de Beatriz Nascimento, "A mulher negra e o amor", aborda com delicadeza e precisão como esse campo da vida é perpassado pelas questões do poder. Já em 2003, Sueli Carneiro produziu o texto "Mulheres negras em movimento: contribuições do feminismo negro", destacando como essa produção teórica continuamente comprova que as mulheres negras se encontram num nó entre racismo, sexismo e pobreza que as empurra para o pior lugar social.

Sobre esse terceiro eixo, vale considerar que hoje em dia (2021) se assume que qualquer corrente de pensamento ou teoria feminista séria está necessariamente comprometida com a problemática do racismo. A luta feminista é obrigatoriamente antirracista: não há como desagregar uma desigualdade da outra na análise da realidade social, uma vez que diversos estudos já comprovaram sua imbricação. Portanto, se no feminismo objetivamos o fomento da igualdade de oportunidades entre mulheres e homens e, além disso, entre mulheres e mulheres, os efeitos da interseccionalidade provam que a variável raça (entre outras) precisa ser considerada.

O último eixo temático do livro, "Em busca de novos caminhos críticos", traz cinco artigos produzidos entre 1992 e 2011. Lourdes Maria Bandeira apresenta um verdadeiro tratado, produzido em 2011, sobre o tema "Violência de gênero: a construção de um campo teórico de investigação", remontando o caminho (de décadas) que culminou no entendimento da violência de gênero como problema social e não como algo pontual ou privado. Essa compreensão, diretamente derivada das lutas e estudos feministas, muda completamente as formas de combater tal violência, conforme vemos na definição:

A violência contra a mulher constitui-se em fenômeno social persistente, multiforme e articulado por facetas psicológica, moral e física. Suas manifestações são maneiras de estabelecer uma relação de submissão ou de poder, implicando sempre situações de medo, isolamento, dependência e intimidação para a mulher. É considerada como uma ação que envolve o uso de força real ou simbólica por parte de outrem com a finalidade de submeter o corpo e a mente à vontade e à liberdade de alguém. (Bandeira, 2019, p. 304). 
Reitera-se, então, que o patriarcado, no seu extremo mais danoso, ofende, machuca e mata mulheres por meio de diversos artifícios e que isso é uma questão estrutural, não um equívoco moral de um ou outro homem individualmente. Tal compreensão expressa uma tremenda virada epistemológica, permitindo justificar, por exemplo, o uso de recursos em políticas públicas específicas.

O quarto eixo ficou mesmo para uma série de discussões teóricas de peso, como a da antropóloga Maria Luiza Heilborn (1992), em "Fazendo gênero? A antropologia da mulher no Brasil", na qual se questiona o que seriam, afinal, uma antropologia da mulher e uma antropologia de gênero, e como esse último termo vinha sendo definido na área; ou ainda a contribuição da historiadora Margareth Rago, "Epistemologia feminista, gênero e história", escrita em 1998, que discute se há e como deveria ser uma epistemologia propriamente feminista. Mais dois artigos ainda compõem esse grupo: o de Ângela Arruda, "Feminismo, gênero e representações sociais", de 2000, atenta para o fato de que "A produção relativa à questão de gênero no campo das representações sociais é reduzida e a utilização da teoria psicossocial das representações sociais pelos estudos de gênero também" (Arruda, 2019, p. 351); e o "Novas subjetividades na pesquisa histórica feminista: uma hermenêutica das diferenças", de Maria Odila Dias (1994), que aponta como uma perspectiva hermenêutica de base gadameriana põe em lugar central uma historicização do cotidiano, da experiência viva das mulheres no decorrer das organizações sociais e como essa forma de análise se afina com pressupostos feministas.

Concluímos esta resenha afirmando que PFB já nasceu um clássico, uma enciclopédia. Fonte segura de retorno às origens e aos desenvolvimentos práticos e teóricos do pensamento feminista no Brasil. Além disso, a obra nos mostra como não só indivíduos, mas também instituições, tiveram e têm papel central na legitimação e cristalização de uma perspectiva de pensamento crítica, por vezes incômoda, e que segue muito necessária.

\section{Referências}

Arruda, A. (2019). Feminismo, gênero e representações sociais. In H. B. de Hollanda (Org.), Pensamento feminista brasileiro: Formação e contexto (pp. 335-355). Bazar do Tempo.

Bandeira, L. M. (2019). Violência de gênero: A construção de um campo teórico de investigação. In H. B. de Hollanda (Org.), Pensamento feminista brasileiro: Formação e contexto (pp. 293-313). Bazar do Tempo.

Hollanda, H. B. de (Org.) (2019). Pensamento feminista brasileiro: Formação e contexto. Bazar do Tempo.

\section{Como citar esta resenha}

Campos, V. P. P. (2021). Pensamento feminista brasileiro: Pensadoras e produções teóricas. [Resenha do livro Pensamento feminista brasileiro: Formação e contexto, de H. B. de Hollanda]. Cadernos de Pesquisa, 51, Resenha e08533. https://doi.org/10.1590/198053148533 